\title{
Altered oscillation patterns and connectivity during picture naming in autism
}

\author{
Isabelle Buard ${ }^{1}$, Sally J. Rogers ${ }^{2}$, Susan Hepburn ${ }^{3}$, Eugene Kronberg' ${ }^{1}$ and Donald C. Rojas ${ }^{\text {* }}$ \\ 1 UCD Magnetoencephalography Lab, Department of Psychiatry, University of Colorado at Denver - Anschutz Medical Campus, Aurora, CO, USA \\ 2 Psychiatry and Behavioral Sciences, UC Davis MIND Institute, Sacramento, CA, USA \\ ${ }^{3}$ University of Colorado/JFK Partners, Aurora, CO, USA
}

\section{Edited by:}

Tal Kenet, Massachusetts General Hospital, USA

\section{Reviewed by:}

Manfred G. Kitzbichler, Harvard Medical School, USA

Guillaume Dumas, Florida Atlantic University, USA

Sheraz Khan, Massachusetts General Hospital, USA

\section{*Correspondence:}

Donald C. Rojas, UCD

Magnetoencephalography Lab, Department of Psychiatry, University of Colorado at Denver - Anschutz Medical Campus, 13001 East 17th PI F546, Aurora, CO 80045, USA e-mail:don.rojas@ucdenver.edu
Similar behavioral deficits are shared between individuals with autism spectrum disorders (ASD) and their first-degree relatives, such as impaired face memory, object recognition, and some language aspects. Functional neuroimaging studies have reported abnormalities in ASD in at least one brain area implicated in those functions, the fusiform gyrus (FG). High frequency oscillations have also been described as abnormal in ASD in a separate line of research. The present study examined whether low- and high-frequency oscillatory power, localized in part to FG and other language-related regions, differs in ASD subjects and first-degree relatives. Twelve individuals with ASD, 16 parents of children with ASD, and 35 healthy controls participated in a picture-naming task using magnetoencephalography (MEG) to assess oscillatory power and connectivity. Relative to controls, we observed reduced evoked high-gamma activity in the right superior temporal gyrus (STG) and reduced high-beta/low-gamma evoked power in the left inferior frontal gyrus (IFG) in the ASD group. Finally, reductions in phase-locked beta-band were also seen in the ASD group relative to controls, especially in the occipital lobes (OCC). First degree relatives, in contrast, exhibited higher high-gamma band power in the left STG compared with controls, as well as increased high-beta/low-gamma evoked power in the left FG. In the left hemisphere, beta- and gamma-band functional connectivity between the IFG and FG and between STG and OCC were higher in the autism group than in controls. This suggests that, contrary to what has been previously described, reduced connectivity is not observed across all scales of observation in autism. The lack of behavioral correlation for the findings warrants some caution in interpreting the relevance of such changes for language function in ASD. Our findings in parents implicates the gamma- and beta-band ranges as potential compensatory phenomena in autism relatives.

Keywords: magnetoencephalography, gamma-band, beta-band, oscillations, functional connectivity, Granger causality, fusiform gyrus, endophenotype

\section{INTRODUCTION}

High-frequency brain activities have a central role in various normal functions (Buzsaki and Draguhn, 2004), including sensory binding (Rodriguez et al., 1999), temporal regulation of neuronal activity during synaptic plasticity (Traub et al., 1998), memory processing (Fell et al., 2001), and large-scale integration (Varela et al., 2001). Several suggestions have been proposed to define the role of gamma-band oscillations ( $30 \mathrm{~Hz}$ and higher) as a correlate of auditory awareness (Makeig and Jung, 1996; Yordanova et al., 2002) or encoding mental representations (Tallon-Baudry and Bertrand, 1999). Moreover, the correlation between gamma synchronization and hemodynamic responses reconciles common findings in fMRI and brain electrophysiology (Niessing et al., 2005). Particularly, gamma-band has been associated with face processing, notably in the fusiform gyrus (FG; Zion-Golumbic and Bentin, 2007; Gao et al., 2013). In autism spectrum disorders (ASD), impairments of gamma oscillations have been previously described in auditory (Wilson et al., 2007; Gandal et al., 2010) and visual domains (Grice et al., 2001; Brown et al., 2005; Milne et al.,
2009; Isler et al., 2010; Stroganova et al., 2012), suggesting a link between high-frequency oscillations and perceptual dysfunction. We have also established that these deficits are seen in adult firstdegree relatives, suggesting that such impairment constitutes an autism endophenotype (Rojas et al., 2008, 2011; McFadden et al., 2012). Lower frequency oscillatory activity has also been described as affected in autism, such as impaired mu wave suppression during action observation (Oberman et al., 2005).

Autism is defined by a triad of core impairments in social interaction, communication, and behavioral flexibility (American Psychiatric Association, 2000). Communication deficits include individual with autism's difficulty using spoken language and gestures, inability to initiate and sustain appropriate conversation and use of inappropriate, repetitive language (Lord et al., 2000). The severity of language impairment is highly variable in autism, ranging from highly verbal to essentially non-verbal (Tager-Flusberg et al., 2009), and it remains the best-known indicator of prognosis in affected individuals (Venter et al., 1992). Within the language domain, problematic pragmatic language use has been repeatedly 
documented among relatives (Losh et al., 2008). Among language impairments, word processing is particularly affected in ASD (Walenski et al., 2008). To examine the prediction of altered lexical processing, we tested subjects with autism on a picture-naming task, in which subjects named pictures of objects. Two major areas in the human brain are responsible for language (Binder et al., 1997): Broca's area (localized to left inferior frontal gyrus, or IFG) which is involved in language production, and Wernicke's area (localized in the superior temporal gyrus, STG) which is thought to be implicated in language processing. Other brain structures may also play a role in language. Among them, the FG has been initially studied as being a part of the visual system specialized in facial recognition (Fusiform Face Area; Kanwisher et al., 1997) because of the importance of face processing to successful social functioning. Its additional role in language processing, called the visual word form area (McCandliss et al., 2003), highlights its relevance for language studies. Interestingly, individuals with ASDs show atypical functional lateralization, with reduced left hemisphere and/or reversed patterns of cortical activation in linguistic experiments (Just et al., 2004; Flagg et al., 2005; Wang et al., 2006; Frye and Beauchamp, 2009).

Hypoactivity in the FG (Schultz et al., 2000) and IFG (Groen et al., 2010) areas has been reported in individuals with autism, suggesting that there should be physiological signatures underlying autism-related language impairments. The objective of this study was to compare gamma-band oscillations in the FG, STG, and IFG, language-related areas of control participants to patients with autism and first-degree relative of persons with ASD during a picture-naming task. Based on prior findings from simple auditory and visual processing experiments, as well as face perception experiments, we expected to observe reduced phase-locked, or evoked gamma-band activity in both the autism group and in parents of individuals with autism compared to controls. Increases in non-phase-locked, or induced gamma-band activity have also been reported in autism (e.g., see Brown etal., 2005; Rojas etal., 2008). We therefore separately analyzed the evoked and induced gamma-band activity in the study.

Building upon previous studies, we found some differential activation in the gamma- and beta-band range in people with autism compared to their first-degree relatives. Patterns of activation were opposite, as parent brains were over-activated while autistic brains showed under-activation. The connectivity analyses and results add to the existing literature by extension to an object naming task and examination of both individuals with autism and first-degree relatives.

\section{MATERIALS AND METHODS SUBJECTS}

Participants were 12 persons with ASD, 16 parents of a child with ASD (PASD), and 35 controls (Table 1). One-way ANOVAs were used to examine demographic variables (age) for significant differences. No significant group differences were present at $p>0.05$ for any of these group characteristics. For ASD subjects, diagnosis was based on convergence of clinical judgment by experimenters using DSM-IV criteria (American Psychiatric Association, 2000), and research reliability trained on the Autism Diagnostic Interview,
Table 1 | Participants characteristics.

\begin{tabular}{lllll}
\hline Measure & Controls & ASD & Parents & $\boldsymbol{p}$-value \\
\hline Age (mean years \pm SD) & $34.2 \pm 11.9$ & $28.3 \pm 13.3$ & $37.9 \pm 5.9$ & 0.082 \\
Handedness score & $0.62 \pm 0.53$ & $0.35 \pm 0.79$ & $0.74 \pm 0.41$ & 0.202 \\
\hline
\end{tabular}

Revised (ADI-R; Lord et al., 1994), and the Autism Diagnostic Observation Schedule (ADOS; Lord et al., 2000). Each of the 16 PASD group subjects had a single child who met the same criteria for ASD as the ASD group participants. The PASD group subjects were not biologically related to the study participants in the ASD group. The healthy comparison subjects had no personal history of developmental, psychiatric, or neurologic disorders, and no family history of developmental disorders. All subjects signed informed consent to participate in the study consistent with the guidelines of the Colorado Multiple Institution Review Board.

Handedness was assessed in all subjects using the Annett Handedness Questionnaire (Annett, 1985). Handedness score means were $0.62 \pm 0.53,0.35 \pm 0.79$, and $0.74 \pm 0.41$ for healthy controls, ASD subjects and PASD, respectively (Table 1). One-way ANOVA (SPSS version 21 - IBM Corp, Armonk, NY, USA) revealed no difference among groups: $F(2,54)=1.65$, $p=0.202$.

\section{STIMULI AND EXPERIMENTAL DESIGN}

The stimuli consisted of 192 black and white line art images from the International Picture Naming Project database ${ }^{1}$, which includes items from the Peabody Picture Vocabulary Test (PPVT; Dunn, 1997), Snodgrass and Vanderwart (1980) and other sources. The pictures represent simple objects such as a shovel or an airplane. Trials consisted of periods of picture stimuli lasting for $1200 \mathrm{~ms}$, followed by a central fixation cross for a random interstimulus interval between 3000 and $5000 \mathrm{~ms}$. Picture stimuli were presented by an LCD projector onto a screen located $45 \mathrm{~cm}$ in front of the subject and subtended an average of $7.27^{\circ}$ horizontal visual angle and $6.02^{\circ}$ vertical visual angle. Subjects were instructed to sub-vocalize (whisper) the name of the object depicted in the image they had just seen as soon as the fixation cross appeared (i.e., after the picture was removed) and received practice trials until they understood the instructions. Sub-vocalization was used instead of overt naming to reduce motion and muscle artifact in the MEG data. The entire recording session lasted approximately $16 \mathrm{~min}$.

\section{MEG DATA ACQUISITION AND PRE-PROCESSING}

We employed a Magnes $3600 \mathrm{WH}$ whole-head MEG device (4-D Neuroimaging, San Diego, CA, USA), which comprises 248 firstorder axial-gradiometer sensors in a helmet-shaped array. Five head position indicator coils attached to the subject's scalp were used to determine the head position with respect to the sensor array. The locations of the coils with respect to three anatomical landmarks (nasion and pre-auricular points) and two extra

${ }^{1}$ http://crl.ucsd.edu/experiments/ipnp/ 
non-fiducial points, as well as the scalp surface were determined with a 3D digitizer (Polhemus, Colchester, VT, USA). Identifying the three fiducial points on an SPM standard head model established the coordinate transformation between MEG and the standard MRI template used for the volume conductor in source modeling.

The MEG signals were acquired in a $0.1-200 \mathrm{~Hz}$ bandwidth and sampled continuously at $508 \mathrm{~Hz}$ and 24-bit quantization. MEG data pre-processing was conducted using the 4-D Neuroimaging software, Fieldtrip ${ }^{2}$ and Statistical Parametric Mapping SPM8 (Wellcome Trust Centre for Neuroimaging, London, UK) implemented in Matlab (2009b; MathWorks, Inc., Natick, MA, USA). Eye movement and blink artifacts were corrected using independent components analysis using the FastICA algorithm (Hyvarinen, 1999). Epochs were then defined of $1200 \mathrm{~ms}$ duration, with a baseline of -200 to $0 \mathrm{~ms}$ pre-stimulus onset and $1000 \mathrm{~ms}$ post-stimulus. Epochs were baseline corrected to remove any DC offset and those trials contaminated by excessively large MEG amplitudes $( \pm 3000 \mathrm{fT})$ were rejected from further analysis. An average of $119( \pm 25)$ artifact free epochs was obtained for source analysis.

\section{MEG SOURCE ANALYSIS AND SOURCE SPACE STATISTICS}

Source analysis was performed in Matlab (2009b; MathWorks, Inc., Natick, MA, USA) using the SPM8 toolbox (Statistical Parametric Mapping; Wellcome Department of Cognitive Neurology, London, UK). Following co-registration of the MEG fiducials with the SPM8 standard template, leadfields were computed using a single shell volume conductor model. Source localization was then performed using a cortically constrained group minimum norm inversion with multiple sparse priors (Litvak et al., 2011), on all subjects' data pooled together from the three groups, which resulted in a common source space images across subjects. The cortical surface used was a standard MNI space surface with 20484 vertices supplied within SPM8. Source analysis was performed on the $35-120 \mathrm{~Hz}$ passband between 100 and $250 \mathrm{~ms}$.

Source space images were submitted to GLM-based statistical analysis using a one-sample $t$-test across subjects in all three groups to find a common set of activated regions for subsequent spectral analyses. Several active brain regions were obtained (Table 2), where activity during the task survived multiple comparison correction, using a false discovery rate (FDR) of $q<0.05$. Among all active regions, we focused on the FG, the inferior frontal gyrus, the STG, and the occipital lobe (OCC) for further ROI-based analyses for three reasons: (1) their relevance to language function, (2) the engagement of visual structures in this specific task, and (3) leadfield correlation is high among closely spaced regions and induces artificial correlation in source waveforms derived from such locations. A limited set of widely spaced ROI is therefore more appropriate given these correlations.

\section{SOURCE WAVEFORMS, SPECTRAL ANALYSES, AND FUNCTIONAL CONNECTIVITY}

Regional time-courses were created via source-space projection (Tesche et al., 1995) from dipoles within each region of interest: left

\footnotetext{
${ }^{2}$ http://fieldtrip.fcdonders.nl
}

Table 2 | List of brain regions that were significantly active (FDR $q<0.05$ ) from source analyses of the $35-120 \mathrm{~Hz}$ band between 100 and $250 \mathrm{~ms}$ post-stimulus.

\begin{tabular}{|c|c|c|c|c|c|}
\hline \multirow{2}{*}{$\begin{array}{l}\text { Region } \\
\text { Pre-cuneus }\end{array}$} & \multirow{2}{*}{$\begin{array}{l}\text { Side } \\
R\end{array}$} & \multicolumn{3}{|c|}{ MNI coordinates } & \multirow{2}{*}{$\begin{array}{l}\boldsymbol{T} \text { value } \\
32.78\end{array}$} \\
\hline & & 4 & -70 & 36 & \\
\hline & $\mathrm{L}$ & -7 & -74 & 42 & 32.12 \\
\hline \multirow[t]{2}{*}{ Cuneus } & $\mathrm{R}$ & 10 & 76 & 38 & 32.62 \\
\hline & $L$ & -10 & -68 & 42 & 31.25 \\
\hline \multirow{2}{*}{$\begin{array}{l}\text { Inferior temporal gyrus area } \\
\text { (includes fusiform gyrus) }\end{array}$} & $\mathrm{R}$ & 54 & -34 & -26 & 11.18 \\
\hline & $L$ & -48 & -56 & -14 & 18.78 \\
\hline Pre-central gyrus & $\mathrm{R}$ & 42 & -14 & 48 & 15.81 \\
\hline Post-central gyrus & $\mathrm{R}$ & 44 & -26 & 46 & 13.96 \\
\hline \multirow[t]{2}{*}{ Superior temporal gyrus } & $\mathrm{R}$ & 50 & -44 & 16 & 11.18 \\
\hline & $\mathrm{L}$ & -50 & -44 & 18 & 16.92 \\
\hline \multirow[t]{2}{*}{ Basal forebrain } & $\mathrm{R}$ & 22 & 10 & -18 & 12.87 \\
\hline & $\mathrm{L}$ & -24 & 8 & -18 & 12.87 \\
\hline \multirow[t]{2}{*}{ Inferior frontal gyrus } & $\mathrm{R}$ & 42 & 28 & 16 & 12.18 \\
\hline & $\mathrm{L}$ & -42 & 24 & 18 & 12.24 \\
\hline Inferior frontal orbital & $\mathrm{L}$ & -34 & 40 & -14 & 9.71 \\
\hline \multirow[t]{2}{*}{ Lobe occipital Superior } & $\mathrm{R}$ & 22 & -80 & 40 & 26.90 \\
\hline & $\mathrm{L}$ & -18 & -80 & 34 & 25.88 \\
\hline \multirow[t]{2}{*}{ Superior frontal gyrus } & $\mathrm{R}$ & 20 & -8 & 64 & 6.69 \\
\hline & $\mathrm{L}$ & -20 & -6 & 66 & 6.70 \\
\hline
\end{tabular}

Regions in bold print were selected for ROI based analyses.

and right FG, IFG, STG, and OCC. We computed the lead field and its pseudoinverse and then we created current source waveform (Ross et al., 2000). Montreal Neurological Institute (MNI) coordinates described in Table 2 were used for this step. Afterward, from those source-space projections were computed time-frequency transforms using a Morlet wavelet decomposition with wave number linearly increasing from 3 to 12 across the frequency range of $10-110 \mathrm{~Hz}$, on the epochs from -200 to $800 \mathrm{~ms}$. For each subject, evoked and induced power, relative to the $200 \mathrm{~ms}$ prestimulus baseline, were calculated, along with the phase-locking factor (PLF; Tallon-Baudry et al., 1996), a measure of inter-trial phase-consistency (also sometimes referred to as intertrial coherence). Mass univariate, non-parametric statistical analyses were performed across the entire time-frequency space, corrected for multiple comparisons using cluster size metrics at FWE $<0.01$. Fieldtrip's cluster-based correction for multiple comparisons uses Monte Carlo randomization to compute a sampling distribution for cluster sizes. Our threshold for cluster formation was set to $p=0.01$ and the number of permutations set to 1000 (Maris and Oostenveld, 2007).

In order to evaluate directional functional connectivity between our regions of interest in the frequency domain, we computed frequency domain Granger causality using the Fieldtrip connectivity analysis functions (Oostenveld et al., 2011), which first involved an autoregressive model fit to the data using the bsmart matlab toolbox (Cui et al., 2008). For these analyses, we downsampled 
the data to $250 \mathrm{~Hz}$ for better model order estimation and submit the data to detrenting, differencing, and pre-whitening. Then, we estimated the model order to be 15 (60 ms) using ARfit toolbox for Matlab (Schneider and Neumaier, 2001). Group comparisons of Granger spectra were analyzed between regions of interest and between the two hemispheres, and corrected for multiple comparisons using the FDR method on the overall set of comparisons, $q<0.1$.

\section{BEHAVIORAL TESTING}

Since we did not measure spoken responses due to concern over excessive motion, the PPVT was performed and scored independently outside of the scanner, on a separate day following the MEG session, as a proxy indication of picture naming performance. The 192 items presented in the scanner contained 62 pictures from the PPVT items. A Kruskal-Wallis one-way analysis of variance was applied to test for statistical differences between groups.

\section{RESULTS}

\section{SOURCE ANALYSIS RESULTS}

Table 2 presents the regions that were significantly active from the source analyses of the 35-120 Hz band between 100 and $250 \mathrm{~ms}$. Indeed, those brain regions included mainly visual and language areas. Among them, the four cortical regions of interest to us during this task (FG, STG, IFG, and OCC) that were selected for source space projections and time-frequency analyses are depicted in Figure 1.

\section{TIME-FREOUENCY RESULTS \\ Fusiform gyrus}

For the left FG, the evoked power was significantly higher in the PASD group, relative to the controls, for high beta/low gammaband activity centered around $35 \mathrm{~Hz}$ and from around 580-700 ms post-stimulus onset (Figure 2). No differences in PLF or induced power were observed for the FG. No difference between the ASD group and both other ones were found in either left or right FG.

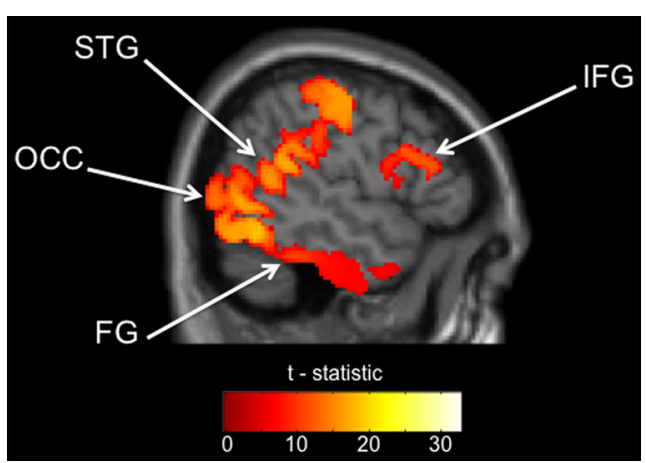

FIGURE 1 | Regions of interest from within source analysis results. Gamma (35-120 Hz) activation maps 100-250 ms after stimulus presentation (FWE, $p<0.05$ ) across all participants. FG, fusiform gyrus; STG, superior temporal gyrus; IFG, inferior frontal gyrus; OCC, occipital lobe. All four clusters used to define our ROls are depicted in this slice, but the exact location of the MNI coordinate used is listed in Table 2.

\section{Superior temporal gyrus}

In the left STG, no significant differences were observed between the $\mathrm{HC}$ and ASD groups, but there was a significant increase in high-gamma evoked power for the PASD group relative to controls between 570 and $630 \mathrm{~ms}$ post-stimulus (Figure 3). No differences in PLF or induced power were seen for the left STG. In the right hemisphere STG, there was a significant decrease in high-gamma evoked power peaking at $900 \mathrm{~ms}$ in the ASD group compared to controls. No differences in PLF or induced power were observed in the right STG between groups.

\section{Inferior frontal gyrus}

For left IFG, there was a significant decrease in evoked power of the high beta/low gamma-band between 630 and 720 ms poststimulus in the control group compared to the autism group (Figure 4). No other significant differences were observed, for any measures within the right IFG and for PLF or induced power in the left IFG.

\section{Occipital lobe}

In both left and right OCC (Figure 5), PLF but not evoked/induced power was significantly reduced in the ASD group in the beta band around 200 (for the right) and 300-400 ms (left). No difference between the parents and controls was found in any measures and any hemispheres.

\section{BEHAVIORAL RESULTS}

All participants were asked to complete the PPVT language test. Figure 6 shows the scores for each group. Comparison between groups did not yield any statistical difference, according to a Kruskall-Wallis test $(p=0.50)$. There were no significant correlations between PPVT performance and either early or late high-gamma-band PLF, evoked or induced power, or those measures in the beta-band, even at uncorrected $p<0.05$.

\section{ALTERED FUNCTIONAL CONNECTIVITY IN THE AUTISM GROUP Left inferior frontal gyrus to left fusiform}

Increased directional connectivity was observed between the left IFG to the left FG (Figure 7, top and horizontal slice) for the autism group compared to the control group. This increase was significant across the high-beta and low gamma frequencies after correction for multiple comparisons (FDR, $q<0.1$ ).

\section{Left superior temporal gyrus to left occipital lobe}

As found between left IFG and FG, there was stronger connectivity in the group of autism participants compared to the controls from the left STG to the left OCC (Figure 7, bottom and right horizontal slice). This was statistically significant within the full beta-and gamma-band ranges.

No other significant differences in connectivity within or between hemispheres, for any frequency, were found among groups. We also observed no significant correlations between the connectivity data and the PPVT.

\section{DISCUSSION}

Our results, if replicated, suggest that altered high- and lowfrequency brain oscillations in regions involved in object and 


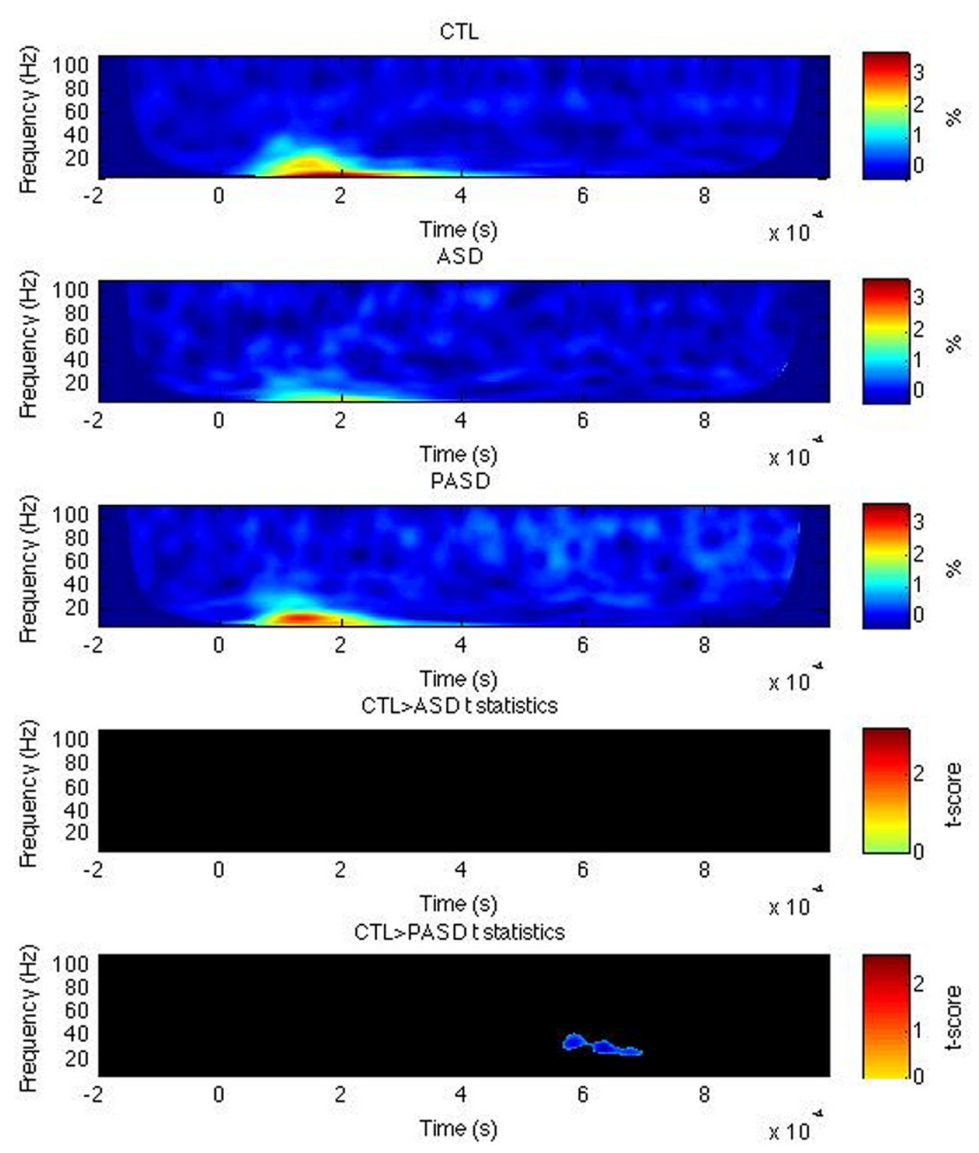

FIGURE 2 | Fusiform gyrus evoked power time-frequency results. Grand average evoked power is shown for each group (three top rows) for the left fusiform gyrus (FG). T-statistic maps are shown in the two bottom rows that illustrate contrasts between controls (CTL) and ASD (row 4) and CTL and parents (PASD; row 5). Masked $t$-score results represent cluster-corrected findings at $p<0.01$
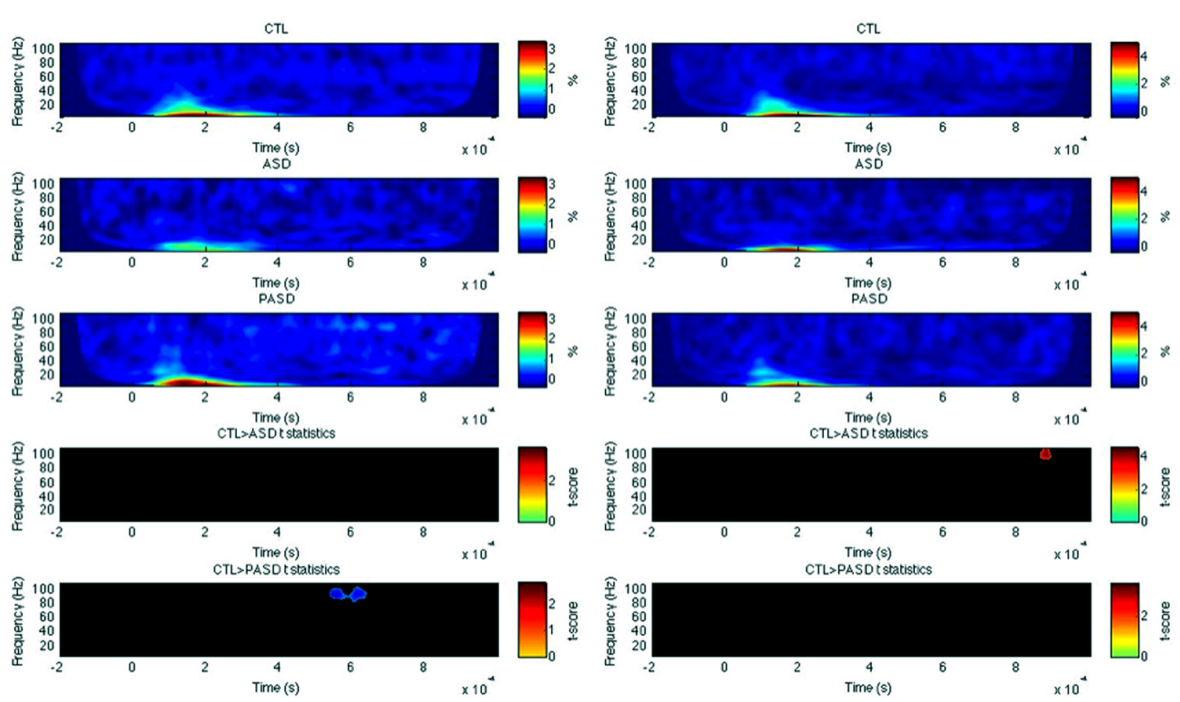

Right

FIGURE 3 | Superior temporal gyrus evoked power time-frequency results. Grand average evoked power is shown for each group (three top rows) for the left and right superior temporal gyrus (STG). T-statistic maps are shown in the two bottom rows that illustrate contrasts between controls $(C T L$ ) and ASD (row 4) and CTL and parents (PASD; row 5). Masked $t$-score results represent cluster-corrected findings at $p<0.01$. 


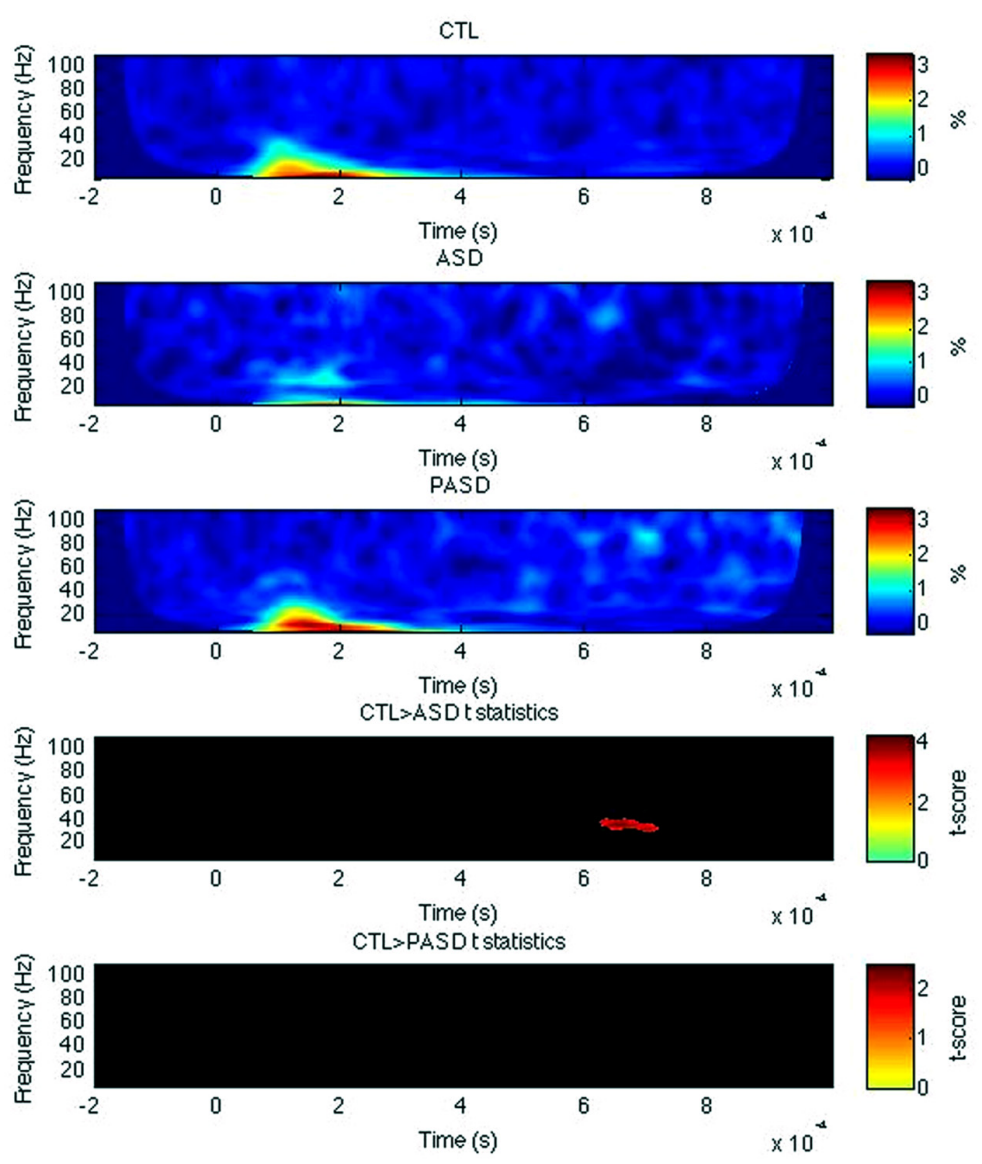

FIGURE 4 | Inferior frontal gyrus evoked power time-frequency results. Grand average evoked power is shown for each group (three top rows) for the left inferior frontal gyrus (IFG). $T$-statistic maps are shown in the two bottom rows that illustrate contrasts between controls (CTL) and ASD (row 4) and CTL and parents (PASD; row 5). Masked $t$-score results represent cluster-corrected findings at $p<0.01$.
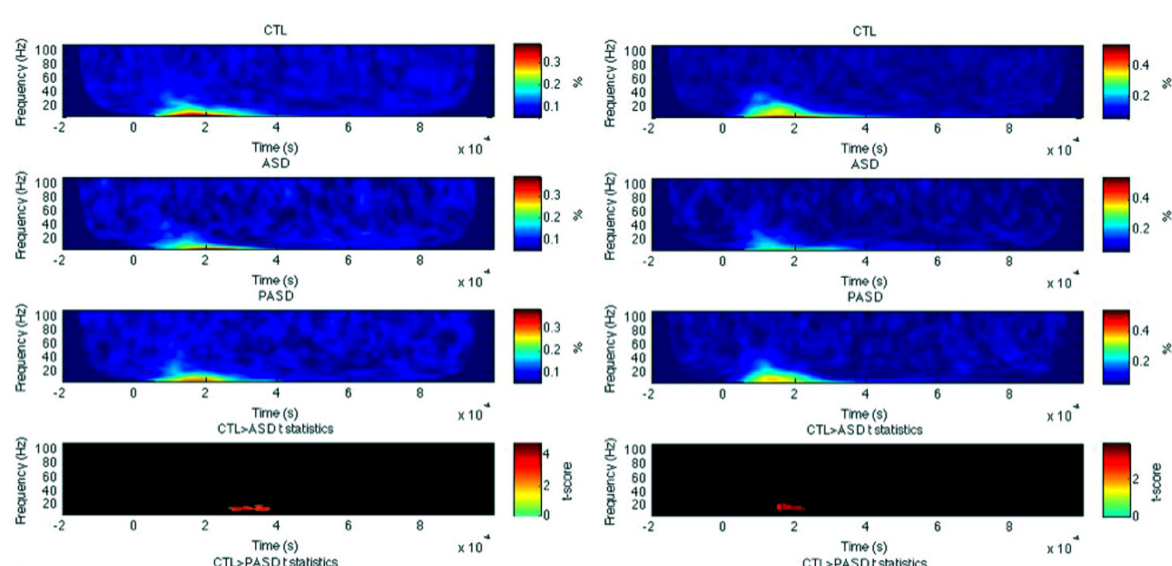

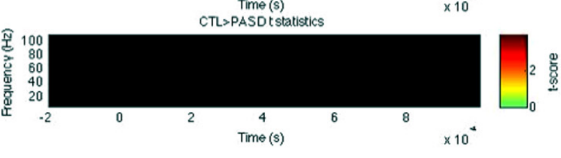

Left

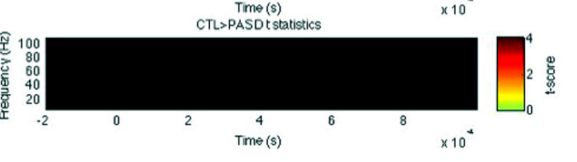

Right
FIGURE 5 | Occipital lobe PLF time-frequency results. Grand average PLF are shown for each group (three top rows) for the left and right occipital lobe (OCC). $T$-statistic maps are shown in the two bottom rows that illustrate contrasts between controls (CTL) and ASD (row 4) and CTL and parents (PASD; row 5). Masked $t$-score results represent cluster-corrected findings at $p<0.01$. 


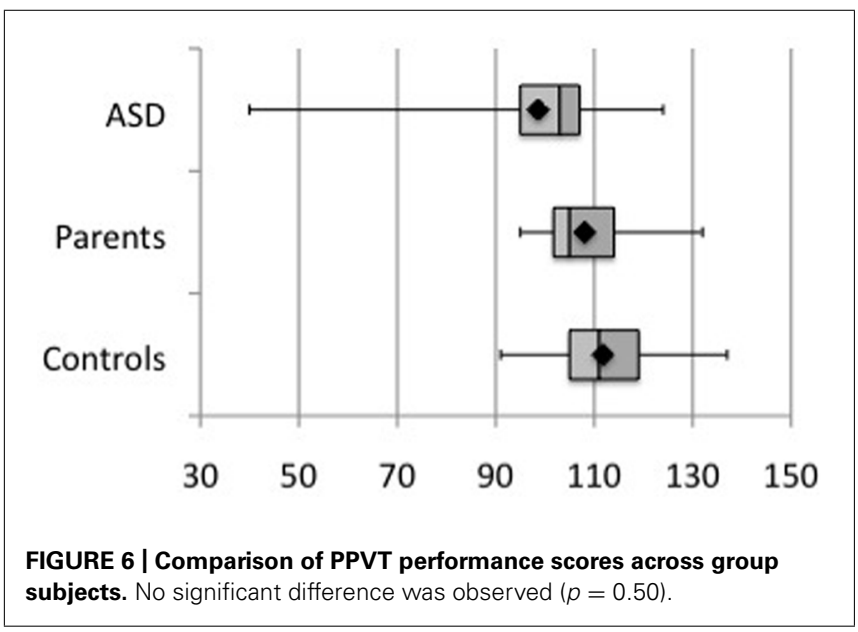

language-related processes are a notable characteristic of autism, and that first-degree relatives share some of those differences. The findings appeared to be regionally and temporally specific in the context of the current task and sample.

\section{CHANGES IN OSCILLATORY POWER AND OVER-CONNECTIVITY IN AUTISM}

Converging evidence from across many studies and a variety of experimental paradigms suggests a gamma-band deficit in ASD (Grice et al., 2001; Brown et al., 2005; Wilson et al., 2007; Rojas et al., 2008, 2011; Gandal etal., 2010; McFadden et al., 2012; Wright et al., 2012; Gao et al., 2013), which has been proposed as a biomarker of autism (Uhlhaas et al., 2010).

In the STG, decreased high-gamma band activity was found. Using auditory-verbal stimulus material, we have already reported similar STG activation trends within autism (Wilson et al., 2007) albeit at a lower gamma-band frequency range of $30-50 \mathrm{~Hz}$. In a language context, both structural and functional differences in the STG have been described in previous autism studies (Herbert et al., 2002; Harris et al., 2006; Hubbard et al., 2012). Altered gamma-band responses have also previously been reported in the STG of children with autism in response to simple, pure tone auditory stimulation (Gandal etal., 2010). In the left IFG, we also found decreased evoked power in the lowgamma band in autism compared to controls. Alterations in oscillations patterns in those language-network structures may be related to language impairments observed in people with autism.

We also note that the low gamma-band findings extended to the beta-range. Indeed, impaired beta-band oscillations have previously been observed in children with ASD compared to healthy controls (Stroganova et al., 2007, 2012). The delineation between the end of one band and beginning of the next is relatively arbitrary, so it is not unexpected to find that high beta and low gamma changes would be present. Additionally, beta-band oscillatory activity is independently known to be responsive to language stimuli (Hirata et al., 2004).

In the OCC, reduced beta PLF was found in both left and right sides of subjects with autism. The presence of those abnormalities in early visual responses is consistent with previous neurophysiological research on face processing (Dawson et al., 2005). Using MEG (Kylliainen et al., 2006), also reported differences in the processing of faces and other complex objects (motorbikes) at $100 \mathrm{~ms}$ in ASD children matched with typically developing controls. Those results and our study showing an impaired oscillation pattern related to object naming in autism suggest that visual brain activity may partly reflect general visual processing differences observed in this population (Jemel et al., 2006).

The observed changes in the STG and IFG occurred later in the post-stimulus window than the early phase-locked changes observed for the OCC. This is in accordance with the involvement of the occipital areas in visual functions, whereas the left FG (Binder et al., 1997; Balsamo et al., 2006) and the STG (Heath et al., 2012) have been reported as active during semantic processing at latter stages in the process of picture naming. A previous MEG study on picture naming reported visual and semantic processing around $0-150$ and 275-400 ms after stimulus presentation (Levelt et al., 1998). Our differences were found between 600 and $900 \mathrm{~ms}$, the timing of which suggests a role in early semantic or covert speech processes.

The autism group exhibited stronger functional connectivity from anterior to posterior language and visual areas compared with the control and parent groups, which may partially explain the impaired activation we found in that group in those regions. This finding is suggestive of differences in long-range neural synchronization present in our patient group. Alteration of long-range connectivity is an often reported finding in autism (Courchesne and Pierce, 2005). For example, reduced nondirectional functional connectivity between anterior and posterior speech areas has been reported previously (Just et al., 2004). Our current result, however, does not support the underconnectivity theory. It should be noted that, apart from our finding of overconnectivity, other evidence also suggest overconnectivity in autism, such as a recent study showing enhanced functional excitation from occipital to frontal areas (Dominguez et al., 2013). In another recent paper, individuals with Asperger syndrome had higher, not lower, fractional anisotropy than controls in a diffusion tensor study of white matter (Roine etal., 2013). Together, these findings suggest that both underconnectivity and overconnectivity can be observed in autism relative to control subjects.

The range of oscillations where ASD people exhibited higher connectivity included both beta and gamma frequencies. Literature reports that gamma rhythms are prevalent in local visual response synchronization, but more distant coherence occurring during multimodal integration between parietal and temporal cortices uses rhythms in the beta range (Roelfsema et al., 1997). Since gamma-band activity is phase-amplitude coupled to lower frequency alpha- and theta-band oscillations, it is possible that the higher connectivity we observe in the gamma-range is a direct effect of the increased connectivity in the beta band between the same regions. A recent MEG paper reported that reduced high-gamma connectivity between the FG and other brain areas was related to decreased local connectivity, as assessed by phaseamplitude coupling to low frequency oscillations in those areas (Khan et al., 2013). One difference between this study and ours 


\section{LIFG TO LFG}
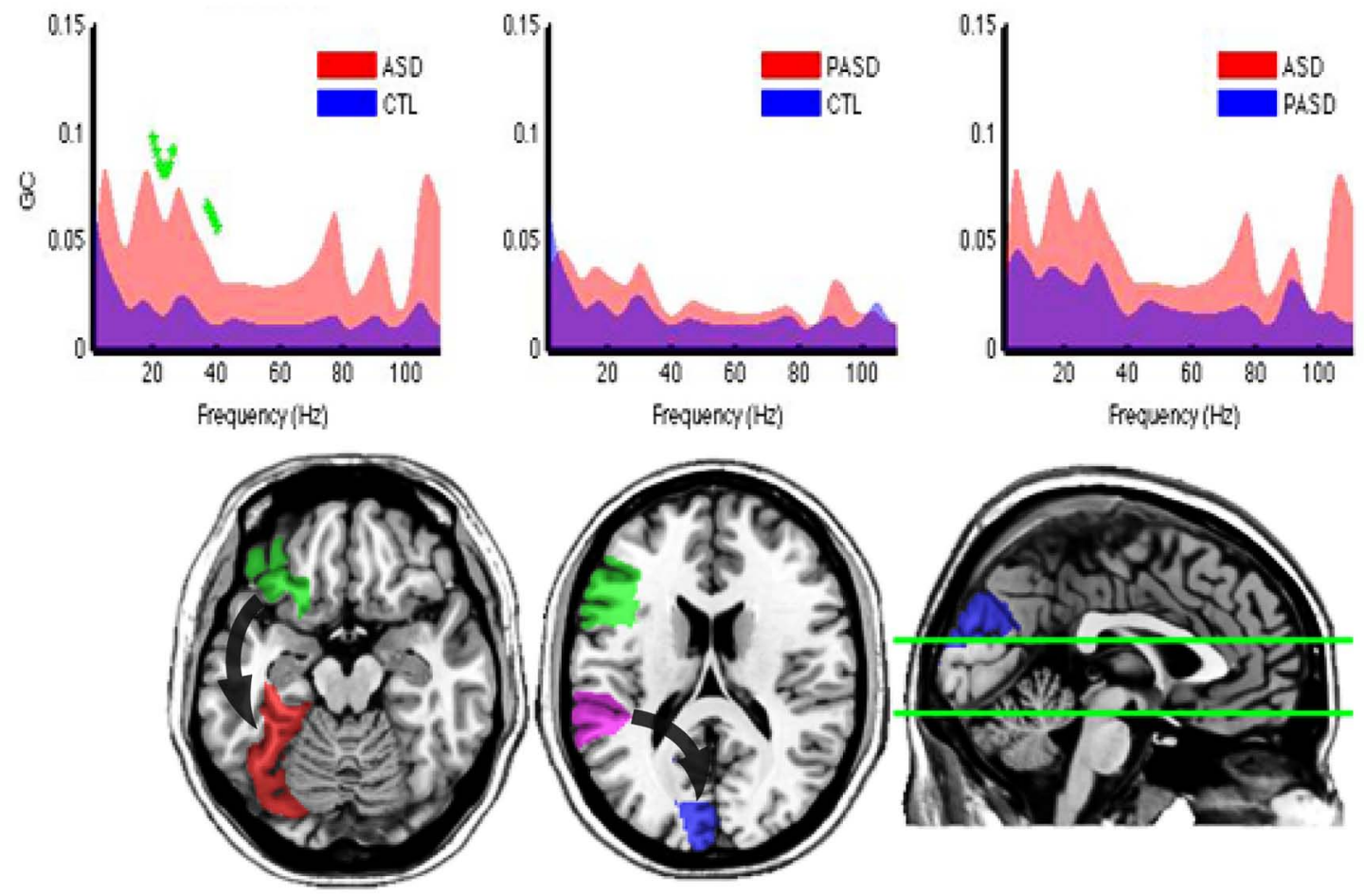

FG

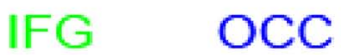

STG
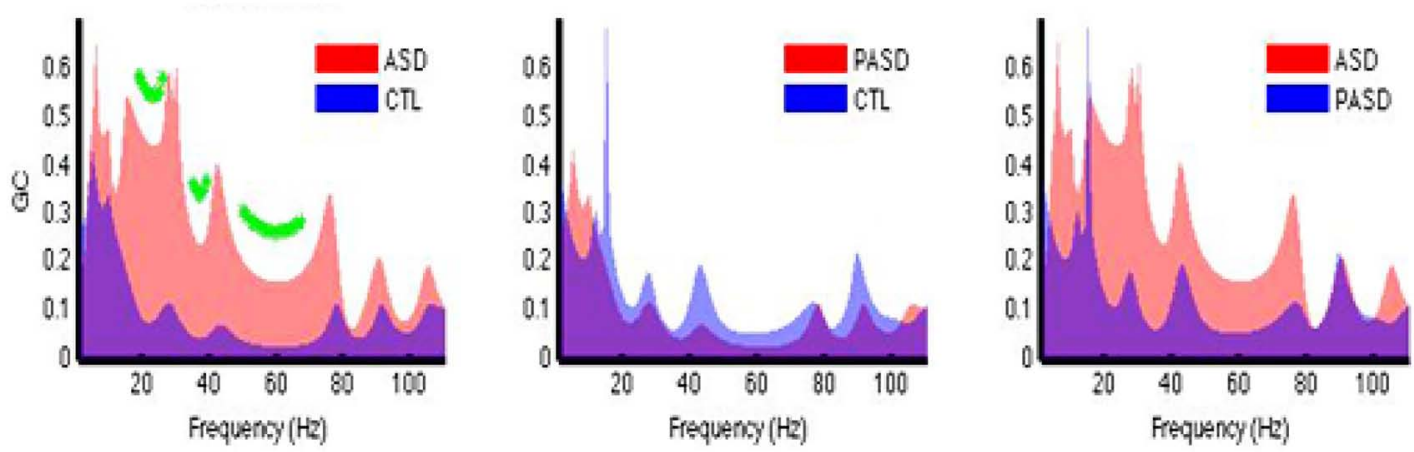

\section{LSTG TO LOCC}

FIGURE 7 | Granger causality results. Granger spectra show functional connectivity between regions of interest with significant differences between the ASD and control groups. GC, Granger causality; FG, fusiform gyrus; STG, superior temporal gyrus; IFG, inferior frontal gyrus; OCC, occipital lobe. The title reading from left to right (e.g., IFG-FG) indicates the direction of causation. Significant group differences are shown with green asterisks (FDR $q<0.1$ ). Brain slices in the middle row illustrate location of those brain areas and flux of information (arrows) between them. was the involvement of the FG relative to the task. In the paper reporting underconnectivity (Khan et al., 2013), the stimuli were faces; in ours, all of the stimuli were non-face objects. Thus, FG might be differentially affected in autism in a task specific manner.

The PPVT scores were not significantly different between the ASD and control groups. Together with the oscillatory and connectivity changes, this might suggest that the increase in communication between language and visual areas could provide a compensatory mechanism for coping with language and/or object naming difficulties. We also did not find any significant relationships between our groups' performance on the behavioral language task and on their gamma-related results. This indicates that this paradigm might not well-suited to study language processes per se in autism, but is perhaps more relevant to issues in early visual perception and object recognition. Consistent with 
this, for example, a previous study reported FG activation during color naming (Price and Devlin, 2003). Finally, we note that although we have speculated concerning language deficits in autism, there is no behavioral evidence for such deficits in our sample. A more severely affected sample might be necessary to establish a relationship, if any, between oscillatory power changes, connectivity, and language deficits in people with autism.

\section{A POTENTIAL COMPENSATORY/PROTECTIVE MECHANISM IN FIRST-DEGREE RELATIVES}

In the FG, evoked power revealed an increase in late high-beta/lowgamma band activity in the PASD group compared to controls. Similarly, we recently published evidence of gamma-band overactivation in the FG in autism first-degree relatives using language stimuli delivered in the auditory modality (McFadden et al., 2012). This increase also extended to the beta-band. Indeed, parents of children with autism show evidence of several areas of difference in common with persons with ASD, such as face memory and object recognition (Wallace et al., 2010), social cognition and working memory (Gokcen et al., 2009), and executive function, the latter being also shared by unaffected siblings (Wong et al., 2006). At the functional level, our group has recently published the evidence of differences in neural patterns associated with phonological processing in first-degree relatives (Wilson et al., 2012).

In the STG, increased activation in the high-gamma band was found in the left hemisphere of parents. Here again, we have already reported similar STG activation trends within autism relatives (McFadden et al., 2012) albeit at a lower gamma-band frequency range of $30-50 \mathrm{~Hz}$. This finding is opposite to what we found in the ASD group. Such differential findings have been reported previously in autism subjects and relatives, such as intact verbal IQ in relatives while probands generally exhibit lower levels relative to performance IQ (Schmidt et al., 2008). In this context, it is possible that the observed over-activity in language-related regions is either a compensatory or protective mechanism.

\section{CONCLUSION}

Our findings of altered beta and gamma oscillations in people with ASD is consistent with a change in neural synchrony, which adds to a growing literature on gamma-band deficits across a number of simple sensory and complex cognitive tasks. The findings suggest that such oscillatory changes may also be relevant to higher order visual object processing and possibly to some language functions, at least in the context of object naming. The lack of similarity between the probands and the parents represents a challenge to the endophenotype interpretation. Alternative explanations include a compensatory or protective mechanism in the first-degree relatives. Impaired connections between posterior and anterior regions of the brain may be a marker of language and/or visual processing differences in autism, but future studies of language impaired individuals with autism will be needed to clarify a specific role, if any, for altered intra-hemispheric connectivity in the language processing deficits observed in the disorder.

\section{ACKNOWLEDGMENTS}

This work was funded by NIH RO1 MH082820 and Cure Autism Now (currently Autism Speaks). The authors of the manuscript declare that they have no conflict of interest to report regarding this manuscript.

\section{REFERENCES}

Annett, M. (1985). Left, Right, Hand, and Brain: The Right Shift Theory. Hove: Cambridge University Press.

American Psychiatric Association. (2000). Diagnostic and Statistical Manual of Mental Disorders, 4th ed. DSM-IV-TR. USA: American Psychiatric Association.

Balsamo, L. M., Xu, B., and Gaillard, W. D. (2006). Language lateralization and the role of the fusiform gyrus in semantic processing in young children. Neuroimage 31, 1306-1314. doi: 10.1016/j.neuroimage.2006.01.027

Binder, J. R., Frost, J. A., Hammeke, T. A., Cox, R. W., Rao, S. M., and Prieto, T. (1997). Human brain language areas identified by functional magnetic resonance imaging. J. Neurosci. 17, 353-362.

Brown, C., Gruber, T., Boucher, J., Rippon, G., and Brock, J. (2005). Gamma abnormalities during perception of illusory figures in autism. Cortex 41, 364-376. doi: 10.1016/S0010-9452(08)70273-9

Buzsaki, G., and Draguhn, A. (2004). Neuronal oscillations in cortical networks. Science 304, 1926-1929. doi: 10.1126/science.1099745

Courchesne, E., and Pierce, K. (2005). Why the frontal cortex in autism might be talking only to itself: local over-connectivity but long-distance disconnection. Curr. Opin. Neurobiol. 15, 225-230. doi: 10.1016/j.conb.2005.03.001

Cui, J., Xu, L., Bressler, S. L., Ding, M., and Liang, H. (2008). BSMART: a Matlab/C toolbox for analysis of multichannel neural time series. Neural Netw. 21, 10941104. doi: 10.1016/j.neunet.2008.05.007

Dawson, G., Webb, S. J., and McPartland, J. (2005). Understanding the nature of face processing impairment in autism: insights from behavioral and electrophysiological studies. Dev. Neuropsychol. 27, 403-424. doi: 10.1207/s15326942dn2703_6

Dominguez, L. G., Velazquez, J. L., and Galan, R. F. (2013). A model of functional brain connectivity and background noise as a biomarker for cognitive phenotypes: application to autism. PLoS ONE 8:e61493. doi: 10.1371/journal.pone.0061493

Dunn, L. M. (1997). PPVT-III: Peabody Picture Vocabulary Test-Third Edition. Circle Pines, MN: American Guidance Service, Inc.

Fell, J., Klaver, P., Lehnertz, K., Grunwald, T., Schaller, C., Elger, C. E., et al. (2001). Human memory formation is accompanied by rhinal-hippocampal coupling and decoupling. Nat. Neurosci. 4, 1259-1264. doi: 10.1038/nn759

Flagg, E. J., Cardy, J. E., Roberts, W., and Roberts, T. P. (2005). Language lateralization development in children with autism: insights from the late field magnetoencephalogram. Neurosci. Lett. 386, 82-87. doi: 10.1016/j.neulet.2005.05.037

Frye, R. E., and Beauchamp, M. S. (2009). Receptive language organization in highfunctioning autism. J. Child Neurol. 24, 231-236. doi: 10.1177/0883073808329572

Gandal, M. J., Edgar, J. C., Ehrlichman, R. S., Mehta, M., Roberts, T. P., and Siegel, S. J. (2010). Validating gamma oscillations and delayed auditory responses as translational biomarkers of autism. Biol. Psychiatry 68, 1100-1106. doi: 10.1016/j.biopsych.2010.09.031

Gao, Z., Goldstein, A., Harpaz, Y., Hansel, M., Zion-Golumbic, E., and Bentin, S. (2013). A magnetoencephalographic study of face processing: M170, gammaband oscillations and source localization. Hum. Brain Mapp. 34, 1783-95 doi: 10.1002/hbm. 22028

Gokcen, S., Bora, E., Erermis, S., Kesikci, H., and Aydin, C. (2009). Theory of mind and verbal working memory deficits in parents of autistic children. Psychiatry Res. 166, 46-53. doi: 10.1016/j.psychres.2007.11.016

Grice, S. J., Spratling, M. W., Karmiloff-Smith, A., Halit, H., Csibra, G., De Haan, M., et al. (2001). Disordered visual processing and oscillatory brain activity in autism and Williams syndrome. Neuroreport 12, 2697-2700. doi: 10.1097/00001756200108280-00021

Groen, W. B., Tesink, C., Petersson, K. M., Van Berkum, J., Van Der Gaag, R. J., Hagoort, P., et al. (2010). Semantic, factual, and social language comprehension in adolescents with autism: an FMRI study. Cereb. Cortex 20, 1937-1945. doi: 10.1093/cercor/bhp264

Harris, G. J., Chabris, C. F., Clark, J., Urban, T., Aharon, I., Steele, S., et al. (2006). Brain activation during semantic processing in autism spectrum disorders via functional magnetic resonance imaging. Brain Cogn. 61, 54-68. doi: 10.1016/j.bandc.2005.12.015 
Heath, S., McMahon, K., Nickels, L., Angwin, A., MacDonald, A., Van Hees, S., et al. (2012). Priming picture naming with a semantic task: an fMRI investigation. PLOS ONE 7:e32809. doi: 10.1371/journal.pone.0032809

Herbert, M. R., Harris, G. J., Adrien, K. T., Ziegler, D. A., Makris, N., Kennedy, D. N., et al. (2002). Abnormal asymmetry in language association cortex in autism. Ann. Neurol. 52, 588-596. doi: 10.1002/ana.10349

Hirata, M., Kato, A., Taniguchi, M., Saitoh, Y., Ninomiya, H., Ihara, A., et al. (2004). Determination of language dominance with synthetic aperture magnetometry: comparison with the Wada test. Neuroimage 23, 46-53. doi: 10.1016/j.neuroimage.2004.05.009

Hubbard, A. L., McNealy, K., Scott-Van Zeeland, A. A., Callan, D. E., Bookheimer, S. Y., and Dapretto, M. (2012). Altered integration of speech and gesture in children with autism spectrum disorders. Brain Behav. 2, 606-619. doi: 10.1002/brb3.81

Hyvarinen, A. (1999). Fast and robust fixed-point algorithms for independent component analysis. IEEE Trans. Neural Netw. 10, 626-634. doi: 10.1109/72.761722

Isler, J. R., Martien, K. M., Grieve, P. G., Stark, R. I., and Herbert, M. R. (2010). Reduced functional connectivity in visual evoked potentials in children with autism spectrum disorder. Clin. Neurophysiol. 121, 2035-2043. doi: 10.1016/j.clinph.2010.05.004

Jemel, B., Mottron, L., and Dawson, M. (2006). Impaired face processing in autism fact or artifact? J. Autism Dev. Disord. 36, 91-106. doi: 10.1007/s10803-0050050-5

Just, M. A., Cherkassky, V. L., Keller, T. A., and Minshew, N. J. (2004) Cortical activation and synchronization during sentence comprehension in highfunctioning autism: evidence of underconnectivity. Brain 127, 1811-1821. doi: 10.1093/brain/awh199

Kanwisher, N., McDermott, J., and Chun, M. M. (1997). The fusiform face area: a module in human extrastriate cortex specialized for face perception. J. Neurosci 17, 4302-4311.

Khan, S., Gramfort, A., Shetty, N. R., Kitzbichler, M. G., Ganesan, S., Moran, J. M., et al. (2013). Local and long-range functional connectivity is reduced in concert in autism spectrum disorders. Proc. Natl. Acad. Sci. U.S.A. 110, 3107-3112. doi $10.1073 /$ pnas. 1214533110

Kylliainen, A., Braeutigam, S., Hietanen, J. K., Swithenby, S. J., and Bailey, A. J. (2006). Face- and gaze-sensitive neural responses in children with autism: a magnetoencephalographic study. Eur. J. Neurosci. 24, 2679-2690. doi: 10.1111/j.1460-9568.2006.05132.x

Levelt, W. J., Praamstra, P., Meyer, A. S., Helenius, P., and Salmelin, R. (1998). An MEG study of picture naming. J. Cogn. Neurosci. 10, 553-567. doi 10.1162/089892998562960

Litvak, V., Mattout, J., Kiebel, S., Phillips, C., Henson, R., Kilner, J., et al. (2011). EEG and MEG data analysis in SPM8. Comput. Intell. Neurosci. 2011, 852961. doi: $10.1155 / 2011 / 852961$

Lord, C., Risi, S., Lambrecht, L., Cook, E. H. Jr., Leventhal, B. L., Dilavore, P. C., et al. (2000). The autism diagnostic observation schedule-generic: a standard measure of social and communication deficits associated with the spectrum of autism. $J$. Autism Dev. Disord. 30, 205-223. doi: 10.1023/A:1005592401947

Lord, C., Rutter, M., and Le Couteur, A. (1994). Autism diagnostic interview-revised: a revised version of a diagnostic interview for caregivers of individuals with possible pervasive developmental disorders. J. Autism Dev. Disord. 24, 659-685. doi: 10.1007/BF02172145

Losh, M., Childress, D., Lam, K., and Piven, J. (2008). Defining key features of the broad autism phenotype: a comparison across parents of multiple- and singleincidence autism families. Am. J. Med. Genet. B Neuropsychiatr. Genet. 147B, 424-433. doi: 10.1002/ajmg.b.30612

Makeig, S., and Jung, T. P. (1996). Tonic, phasic, and transient EEG correlates of auditory awareness in drowsiness. Brain Res. Cogn. Brain Res. 4, 15-25. doi: 10.1016/0926-6410(95)00042-9

Maris, E., and Oostenveld, R. (2007). Nonparametric statistical testing of EEG- and MEG-data. J. Neurosci. Methods 164, 177-190. doi: 10.1016/j.jneumeth.2007.03.024

McCandliss, B. D., Cohen, L., and Dehaene, S. (2003). The visual word form area: expertise for reading in the fusiform gyrus. Trends Cogn. Sci. 7, 293-299. doi: 10.1016/S1364-6613(03)00134-7

McFadden, K. L., Hepburn, S., Winterrowd, E., Schmidt, G. L., and Rojas, D. C. (2012). Abnormalities in gamma-band responses to language stimuli in firstdegree relatives of children with autism spectrum disorder: an MEG study. BMC Psychiatry 12:213. doi: 10.1186/1471-244X-12-213
Milne, E., Scope, A., Pascalis, O., Buckley, D., and Makeig, S. (2009). Independent component analysis reveals atypical electroencephalographic activity during visual perception in individuals with autism. Biol. Psychiatry 65, 22-30. doi: 10.1016/j.biopsych.2008.07.017

Niessing, J., Ebisch, B., Schmidt, K. E., Niessing, M., Singer, W., and Galuske, R. A. (2005). Hemodynamic signals correlate tightly with synchronized gamma oscillations. Science 309, 948-951. doi: 10.1126/science.1110948

Oberman, L. M., Hubbard, E. M., McCleery, J. P., Altschuler, E. L., Ramachandran, V. S., and Pineda, J. A. (2005). EEG evidence for mirror neuron dysfunction in autism spectrum disorders. Brain Res. Cogn. Brain Res. 24, 190-198. doi: 10.1016/j.cogbrainres.2005.01.014

Oostenveld, R., Fries, P., Maris, E., and Schoffelen, J. M. (2011). FieldTrip: open source software for advanced analysis of MEG, EEG, and invasive electrophysiological data. Comput. Intell. Neurosci. 2011, 156869. doi: 10.1155/2011/156869

Price, C. J., and Devlin, J. T. (2003). The myth of the visual word form area. Neuroimage 19, 473-481. doi: 10.1016/S1053-8119(03)00084-3

Rodriguez, E., George, N., Lachaux, J. P., Martinerie, J., Renault, B., and Varela, F. J. (1999). Perception's shadow: long-distance synchronization of human brain activity. Nature 397, 430-433. doi: 10.1038/17120

Roelfsema, P. R., Engel, A. K., Konig, P., and Singer, W. (1997). Visuomotor integration is associated with zero time-lag synchronization among cortical areas. Nature 385, 157-161. doi: 10.1038/385157a0

Roine, U., Roine, T., Salmi, J., Nieminen-Von Wendt, T., Leppamaki, S., Rintahaka, P., et al. (2013). Increased coherence of white matter fiber tract organization in adults with Asperger syndrome: a diffusion tensor imaging study. Autism Res. doi: 10.1002/aur.1332 [Epub ahead of print].

Rojas, D. C., Maharajh, K., Teale, P., and Rogers, S. J. (2008). Reduced neural synchronization of gamma-band MEG oscillations in first-degree relatives of children with autism. BMC Psychiatry 8:66. doi: 10.1186/1471244X-8-66

Rojas, D. C., Teale, P. D., Maharajh, K., Kronberg, E., Youngpeter, K., Wilson, L. B., et al. (2011). Transient and steady-state auditory gamma-band responses in first-degree relatives of people with autism spectrum disorder. Mol. Autism 2, 11. doi: 10.1186/2040-2392-2-11

Ross, B., Borgmann, C., Draganova, R., Roberts, L. E., and Pantev, C. (2000). A high-precision magnetoencephalographic study of human auditory steady-state responses to amplitude-modulated tones. J. Acoust. Soc. Am. 108, 679-691. doi: 10.1121/1.429600

Schmidt, G. L., Kimel, L. K., Winterrowd, E., Pennington, B. F., Hepburn, S. L., and Rojas, D. C. (2008). Impairments in phonological processing and nonverbal intellectual function in parents of children with autism. J. Clin. Exp. Neuropsychol. 30, 557-567. doi: 10.1080/13803390701551225

Schneider, T., and Neumaier, A. (2001). Algorithm 808: ARfit - a Matlab package for the estimation of parameters and eigenmodes of multivariate autoregressive models. ACM Trans. Math. Softw. 27, 58-65. doi: 10.1145/382043.382316

Schultz, R. T., Gauthier, I., Klin, A., Fulbright, R. K., Anderson, A. W., Volkmar, F, et al. (2000). Abnormal ventral temporal cortical activity during face discrimination among individuals with autism and Asperger syndrome. Arch. Gen. Psychiatry 57, 331-340. doi: 10.1001/archpsyc.57.4.331

Snodgrass, J. G., and Vanderwart, M. (1980). A standardized set of 260 pictures: norms for name agreement, image agreement, familiarity and visual complexity. J. Exp. Psychol. Hum. Learn. 6, 174-215. doi: 10.1037/0278-7393.6.2.174

Stroganova, T. A., Orekhova, E. V., Prokofyev, A. O., Posikera, I. N., Morozov, A. A., Obukhov, Y. V., et al. (2007). Inverted event-related potentials response to illusory contour in boys with autism. Neuroreport 18, 931-935. doi: 10.1097/WNR.0b013e32811e151b

Stroganova, T. A., Orekhova, E. V., Prokofyev, A. O., Tsetlin, M. M., Gratchev, V. V., Morozov, A. A., et al. (2012). High-frequency oscillatory response to illusory contour in typically developing boys and boys with autism spectrum disorders. Cortex 48, 701-717. doi: 10.1016/j.cortex.2011.02.016

Tager-Flusberg, H., Rogers, S., Cooper, J., Landa, R., Lord, C., Paul, R., et al. (2009). Defining spoken language benchmarks and selecting measures of expressive language development for young children with autism spectrum disorders. J. Speech Lang. Hear. Res. 52, 643-652. doi: 10.1044/1092-4388(2009/080136)

Tallon-Baudry, C., and Bertrand, O. (1999). Oscillatory gamma activity in humans and its role in object representation. Trends Cogn. Sci. 3, 151-162. doi: 10.1016/S1364-6613(99)01299-1 
Tallon-Baudry, C., Bertrand, O., Delpuech, C., and Pernier, J. (1996). Stimulus specificity of phase-locked and non-phase-locked $40 \mathrm{~Hz}$ visual responses in human. $J$. Neurosci. 16, 4240-4249.

Tesche, C. D., Uusitalo, M. A., Ilmoniemi, R. J., Huotilainen, M., Kajola, M., and Salonen, O. (1995). Signal-space projections of MEG data characterize both distributed and well-localized neuronal sources. Electroencephalogr. Clin. Neurophysiol. 95, 189-200. doi: 10.1016/0013-4694(95)00064-6

Traub, R. D., Spruston, N., Soltesz, I., Konnerth, A., Whittington, M. A., and Jefferys, G. R. (1998). Gamma-frequency oscillations: a neuronal population phenomenon, regulated by synaptic and intrinsic cellular processes, and inducing synaptic plasticity. Prog. Neurobiol. 55, 563-575. doi: 10.1016/S03010082(98)00020-3

Uhlhaas, P. J., Roux, F., Rodriguez, E., Rotarska-Jagiela, A., and Singer, W. (2010). Neural synchrony and the development of cortical networks. Trends Cogn. Sci. 14, 72-80. doi: 10.1016/j.tics.2009.12.002

Varela, F., Lachaux, J. P., Rodriguez, E., and Martinerie, J. (2001). The brainweb: phase synchronization and large-scale integration. Nat. Rev. Neurosci. 2, 229-239. doi: $10.1038 / 35067550$

Venter, A., Lord, C., and Schopler, E. (1992). A follow-up study of high-functioning autistic children. J. Child Psychol. Psychiatry 33, 489-507. doi: 10.1111/j.14697610.1992.tb00887.x

Walenski, M., Mostofsky, S. H., Gidley-Larson, J. C., and Ullman, M. T. (2008). Brief report: enhanced picture naming in autism. J. Autism Dev. Disord. 38, 1395-1399. doi: 10.1007/s10803-007-0513-y

Wallace, S., Sebastian, C., Pellicano, E., Parr, J., and Bailey, A. (2010). Face processing abilities in relatives of individuals with ASD. Autism Res. 3, 345-349. doi: 10.1002/aur.161

Wang, A. T., Lee, S. S., Sigman, M., and Dapretto, M. (2006). Neural basis of irony comprehension in children with autism: the role of prosody and context. Brain 129, 932-943. doi: 10.1093/brain/awl032

Wilson, L. B., Tregellas, J. R., Slason, E., Pasko, B. E., Hepburn, S., and Rojas, D. C. (2012). Phonological processing in first-degree relatives of individuals with autism: an fMRI study. Hum. Brain Mapp. 34, 1447-1463. doi: 10.1002/hbm.22001
Wilson, T. W., Rojas, D. C., Reite, M. L., Teale, P. D., and Rogers, S. J. (2007). Children and adolescents with autism exhibit reduced MEG steady-state gamma responses. Biol. Psychiatry 62, 192-197. doi: 10.1016/j.biopsych.2006.07.002

Wong, D., Maybery, M., Bishop, D. V., Maley, A., and Hallmayer, J. (2006). Profiles of executive function in parents and siblings of individuals with autism spectrum disorders. Genes Brain Behav. 5, 561-576. doi: 10.1111/j.1601-183X.2005.00199.x Wright, B., Alderson-Day, B., Prendergast, G., Bennett, S., Jordan, J., Whitton, C., et al. (2012). Gamma activation in young people with autism spectrum disorders and typically-developing controls when viewing emotions on faces. PLoS ONE 7:e41326. doi: 10.1371/journal.pone.0041326

Yordanova, J., Kolev, V., Heinrich, H., Woerner, W., Banaschewski, T., and Rothenberger, A. (2002). Developmental event-related gamma oscillations: effects of auditory attention. Eur. J. Neurosci. 16, 2214-2224. doi: 10.1046/j.14609568.2002.02286.x

Zion-Golumbic, E., and Bentin, S. (2007). Dissociated neural mechanisms for face detection and configural encoding: evidence from N170 and induced gammaband oscillation effects. Cereb. Cortex 17, 1741-1749. doi: 10.1093/cercor/bhl100

Conflict of Interest Statement: The authors declare that the research was conducted in the absence of any commercial or financial relationships that could be construed as a potential conflict of interest.

Received: 15 June 2013; accepted: 17 October 2013; published online: 08 November 2013.

Citation: Buard I, Rogers SJ, Hepburn S, Kronberg E and Rojas DC (2013) Altered oscillation patterns and connectivity during picture naming in autism. Front. Hum. Neurosci. 7:742. doi: 10.3389/fnhum.2013.00742

This article was submitted to the journal Frontiers in Human Neuroscience.

Copyright (C) 2013 Buard, Rogers, Hepburn, Kronberg and Rojas. This is an open-access article distributed under the terms of the Creative Commons Attribution License (CC $B Y)$. The use, distribution or reproduction in other forums is permitted, provided the original author(s) or licensor are credited and that the original publication in this journal is cited, in accordance with accepted academic practice. No use, distribution or reproduction is permitted which does not comply with these terms. 